\title{
Redimensionando El Churcal: aportes sobre su estructuración espacial a partir de nuevos datos planimétricos y arquitectónicos (valle Calchaquí, Salta)
}

\author{
Marina Sprovieri \\ (iD) https://orcid.org/0000-0002-8211-3978 \\ División Arqueología, Facultad de Ciencias Naturales y Museo, Universidad Nacional de La Plata (UNLP) - Consejo \\ Nacional de Investigaciones Científicas y Técnicas (CONICET). Laboratorio 102, Anexo Museo, Av. 122 y 60, (CP \\ B1900FWA), La Plata, Buenos Aires, Argentina. E-mail: msprovieri@fcnym.unlp.edu.ar
}

\author{
Santiago Barbich \\ (DD https://orcid.org/0000-0003-1483-1027 \\ División Arqueología, Facultad de Ciencias Naturales y Museo, Universidad Nacional de La Plata (UNLP) - Consejo \\ Nacional de Investigaciones Científicas y Técnicas (CONICET). Laboratorio 102, Anexo Museo, Av. 122 y 60, (CP \\ B1900FWA), La Plata, Buenos Aires, Argentina. E-mail: noestusombra@gmail.com
}

Recibido: 28 de febrero de 2020

Aceptado: 15 de julio de 2020

En memoria de Lidia Baldini (1952-2016), nuestra directora y compañera, cuyas valiosas investigaciones en El Churcal esperamos continuar con capacidad y responsabilidad.

\begin{abstract}
Resumen
El objetivo de este trabajo es contribuir al conocimiento de la estructuración espacial y el funcionamiento de El Churcal (valle Calchaquí, provincia de Salta), un asentamiento conglomerado tardío de gran envergadura pero con escasa investigación sistemática. Para ello se presenta y examina información nueva y detallada de sus dimensiones, límites y emplazamiento general, obtenida en recientes prospecciones y registros en el terreno. A su vez, se presenta la planimetría de una porción relevante del poblado, registrada con Estación Total y reconstruida digitalmente y se analiza su arquitectura y organización espacial mediante la consideración de variables cuanti y cualitativas. En base a ello fue posible obtener una visión más ajustada de la complejidad de este asentamiento y resaltarlo, no únicamente por sus grandes dimensiones sino particularmente por la cantidad, diversidad, distribución y asociación de estructuras y rasgos. Asimismo, esto permitió proponer sectorizaciones espaciales en la porción relevada y plantear una potencial utilización diferencial de sus espacios.
\end{abstract}




\title{
Redimentioning El Churcal: contribution to the study of its spatial structure from new planimetric and architectural data (Calchaquí Valley, Salta)
}

\begin{abstract}
This paper aims to contribute to the study of the spatial structure and functioning of El Churcal (Calchaquí Valley, Salta Province), a large-scale late conglomerate settlement but with scarce systematic research. We present and examine new and detailed information obtained in recent surveys and fieldwork, regarding its dimensions, limits, and position. Moreover, we present the planimetry of an important portion of the settlement, which was registered with a Total Station and reconstructed digitally. This allowed us to analyze its architecture and spatial organization, considering both quantitative and qualitative variables. As a result, we were able to obtain a more accurate understanding of the settlement's complexity and to highlight not only its dimensions, but also the amount, diversity, distribution, and association of its structures and features. Additionally, this allowed us to propose spatial zonings in the surveyed area and suggest the potential differential use of their spaces.
\end{abstract}

KEYWORDS: Spatiality; Complexity; Regional Developments Period; Northwestern Argentina.

\section{Introducción y contexto regional}

El espacio, al ser entendido como construcción social, se aparta de su concepción como dimensión abstracta, universal y ahistórica y adquiere una significancia relacional, en tanto es creado a partir de las relaciones entre personas, lugares y prácticas a lo largo del tiempo. La constitución de las espacialidades se da en el mismo devenir de las vidas y acciones de las generaciones que las han habitado y experimentado. En ese proceso de habitar existe una constitución simultánea y continua de los lugares y las personas (Hayden, 1997; Ingold, 1993, 2000; Tilley, 1994). Un testimonio de ese proceso de habitar son los poblados construidos por las sociedades agroalfareras tardías ${ }^{1}$ del noroeste argentino. En particular, en el valle Calchaquí central (VCC), provincia de Salta, el estudio durante las últimas décadas de la arquitectura, estructuración, emplazamiento y cronología de los asentamientos tardíos ha permitido avanzar en el conocimiento de las maneras de ocupación humana en el área y sus cambios en el tiempo.

Las investigaciones desarrolladas por Lidia Baldini se dirigieron a indagar en los modos de ocupación del valle durante el período de Desarrollos Regionales (PDR), realizando amplias prospecciones regionales que aportaron el registro de numerosos sitios y valiosa información sobre arquitectura, emplazamiento, recursos, etc. Se ha propuesto que la ocupación del espacio en el VCC se encontró influenciada por la posibilidad de acceso a tierras aptas para agricultura, mostrando una tendencia hacia la instalación de conglomerados de envergadura en terrazas inmediatamente por encima de la faja irrigada del río, especialmente en el valle troncal (Baldini y De Feo, 2000). Por su parte, sobre las quebradas tributarias occidentales, se emplazan conjuntos habitacionales de dimensiones reducidas asociados a espacios acondicionados para el desarrollo de actividades agrícolas (Baldini y De Feo, 2000). Esta magnitud y disposición espacial diferencial de los sitios ha llevado a plantear la posibilidad de que los asentamientos con mayor densidad poblacional articularan las instalaciones del interior de las cuencas produciendo una integración de las poblaciones transversal al eje del río Calchaquí.

1 Con tardía/o se hace referencia a una época que abarca al período de Desarrollos Regionales (900-1430/70 d.C.) y al período Inka (1430/70-1536 d.C.). 
Esto se evidencia especialmente en las cuencas de los ríos Cachi y Molinos, que permiten accesibilidad a terrenos con alta productividad agroganadera, posibilidad para el desarrollo de diferentes recursos económicos y constituyen vías de comunicación interregional (Baldini, Baffi, Quiroga y Villamayor, 2004; Baldini y De Feo, 2000; Baldini y Villamayor, 2007).

Por otra parte, las investigaciones dirigidas por Verónica Williams apuntaron al estudio de patrones arquitectónicos y de modos de uso del espacio durante el segundo milenio (PDR-Inka-Colonial) en la cuenca de Molinos, en particular el sector de los ríos Tacuil-Amaicha y en la cuenca de Angastaco. En estas áreas de quebradas altas que comunican el valle Calchaquí con el ámbito puneño ha ubicado alrededor de 25 asentamientos arqueológicos: de tipo pukará, pequeños semiconglomerados en cotas más bajas, extensas áreas de cultivo, arte rupestre, tramos de caminos y santuarios de altura (Villegas, 2011; Williams, Korstanje, Cuenya y Villegas, 2010). De acuerdo con estos relevamientos, las ocupaciones del PDR están representadas por numerosos pukarás, naturalmente defendidos y estratégicamente ubicados sobre las vías de circulación naturales, lo que sugiere un interés por controlar los bienes, recursos y personas que circularon por tales quebradas. Sin embargo, durante la ocupación inka se produce una reconfiguración del paisaje, observándose una instalación de asentamientos estatales en el fondo del valle troncal y el piso de puna (pukarás, tambos y sitios agrícolas), siendo menor la presencia inka en las quebradas altas (Williams, 2010; Williams y Villegas, 2017).

A nivel de los asentamientos, el análisis de aspectos arquitectónicos, espaciales y materiales de algunos poblados tardíos ha permitido conocer más sobre su funcionamiento y formas de habitarlos (Alfaro de Lanzone, 1985; DeMarrais, 1997; González y Díaz, 1992; Tarragó, 1980; Tarragó, Carrara y Díaz, 1979; Tarragó y De Lorenzi 1976, entre otros). Recientemente, a partir de nuevas investigaciones en sitios de la cuenca del río Cachi y alrededores, se sostiene la existencia de una semejanza generalizada en los tipos de estructuras que los componen, distribución, técnicas y calidades constructivas, dimensiones, morfologías y formas de circulación internas, a la vez que una ausencia de sectores jerárquicamente distintos o construcciones de carácter monumental (Acuto, Amuedo, Kergaravat, Goldin y Gamarra, 2008; Acuto, Troncoso y Ferrari, 2012; Ferrari, 2012; Kergaravat, Ferrari y Acuto, 2015). Esto ha llevado a plantear que la espacialidad de los asentamientos fomentaba un sentido de integración e igualdad social en la vida cotidiana (Acuto, 2007; Acuto et al., 2008).

Más allá de estas semejanzas, el avance y la profundidad en las investigaciones han permitido detectar también particularidades en aspectos formales, diseño espacial y funcionalidad de ciertos espacios al interior de los asentamientos. Mediante nuevas prospecciones y relevamientos en el sitio Las Pailas (Figura 1) se ha reconocido una nueva área de cultivo y se han caracterizado más profundamente algunas de sus estructuras como cuadros de cultivo y canales de riego aéreos y subterráneos (Páez, Giovannetti y Raffino, 2012; Prieto, Besa, Marinangeli, Riegler y Páez, 2012). Por otra parte, estudios enfocados en el área residencial de Las Pailas han detectado una variación en la técnica constructiva que se aparta de la predominante construcción semisubterránea de los poblados tardíos, lo cual generaría ciertas restricciones en la permeabilidad física y visual (Acuto, 2007; Kergaravat et al., 2015). También en Las Pailas, se han identificado espacios vinculados a la dinámica ritual y la realización de ofrendas votivas en el sitio (Páez, Lynch y Besa, 2014), así como seis espacios de congregación en su espacio habitacional (Kergaravat, 2013; Kergaravat et al., 2015). A su vez, en el sitio Mariscal (Figura 1), se ha reconocido una estructura de características especiales, diferente a las edificaciones vinculadas a la vida cotidiana, que fue interpretada como un espacio de reunión (Kergaravat, 2013). Por otra parte, avances en el estudio de un sector particular del sitio La Paya (Figura 1) mostraron la 
existencia de estructuras que pueden diferenciarse según: su composición, su tamaño y su comunicación entre sí y con el exterior. Estas características resultan relevantes para avanzar en la comprensión de cómo habrían sido utilizados estos diversos espacios y de la estructuración general del sitio (Sprovieri y Barbich, 2017).

Algunos de estos aspectos del habitar en los poblados de la región se vieron transformados durante la ocupación inka (Acuto, 1999; D'Altroy et al., 2000; González y Díaz, 1992; Williams, 2004; entre otros). La construcción de nuevos asentamientos inkas, así como la modificación de la arquitectura, la circulación y la visibilidad de algunos edificios o sectores dentro de poblados locales crearon nuevas formas de movimiento, interacción y posibilidades de experimentar los espacios (Acuto et al., 2012; Ferrari, 2016).

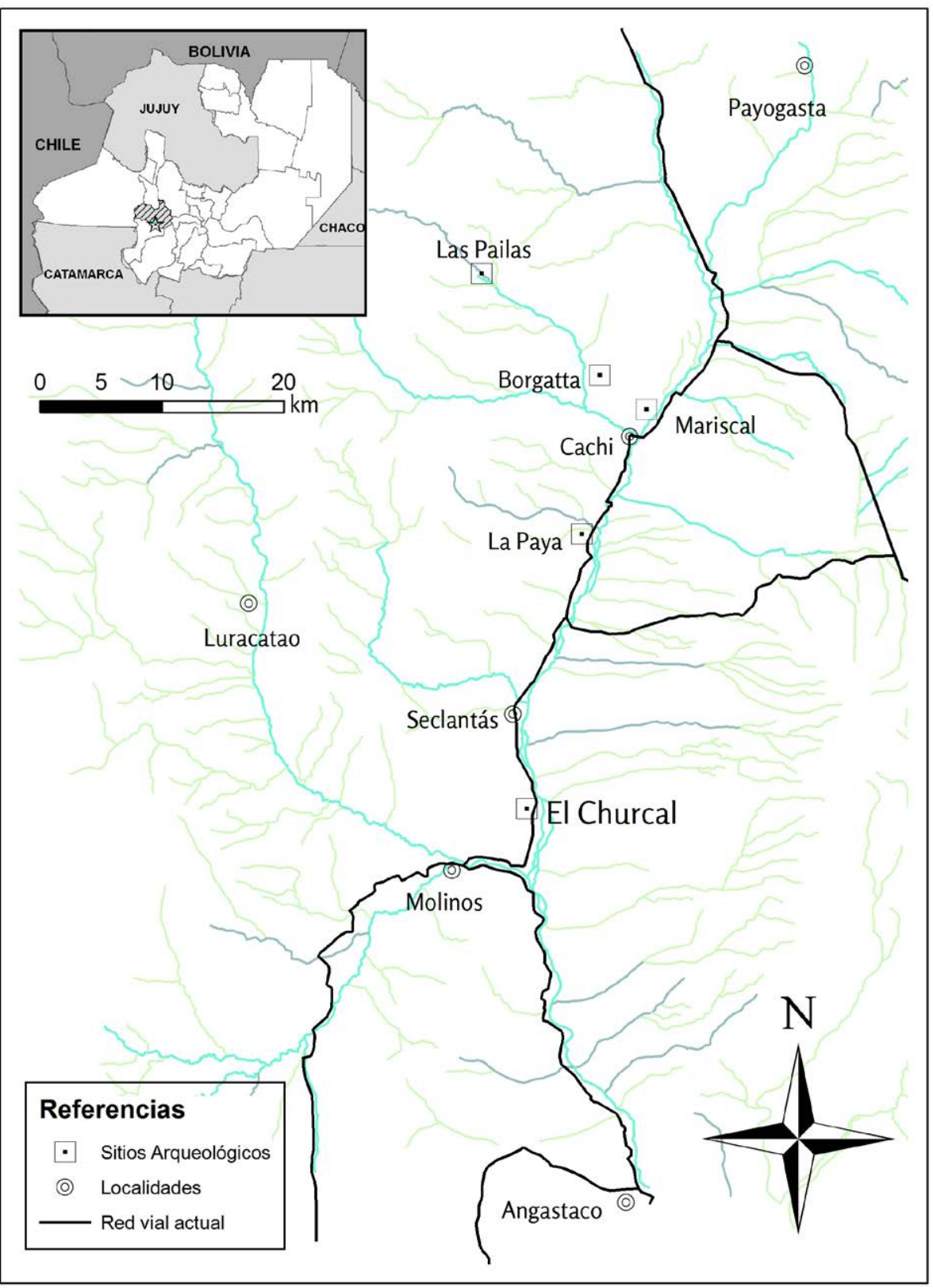

Figura 1. Mapa del valle Calchaquí con la ubicación de El Churcal y otros sitios y localidades mencionadas. 
En este contexto regional, el poblado de El Churcal (Figura 1), de gran envergadura pero con escasa investigación sistemática, se plantea como un registro valioso para aportar a la comprensión de la ocupación tardía de la región y de los modos de habitar calchaquíes. De manera específica, este trabajo busca contribuir al conocimiento de la estructuración espacial y funcionamiento de este asentamiento. Nuestra propuesta de trabajo es que se trata de un poblado de significativa complejidad respecto a otros de la región, debido a la cantidad, diversidad y distribución de las construcciones y rasgos que lo componen, la existencia de mayores sectorizaciones internas que las señaladas hasta el momento y el uso diferencial de espacios. Esto se evaluará a partir de la presentación y análisis de información nueva y detallada de las dimensiones, límites y emplazamiento general del poblado y de la arquitectura y organización espacial de una porción relevante del mismo.

\section{El asentamiento de El Churcal y sus antecedentes de investigación}

El asentamiento de El Churcal (SSalMol2) se localiza en un cono de deyección de forma irregular, ubicado en la margen derecha del río Calchaquí, a unos $10 \mathrm{~km}$ de la localidad actual de Molinos (Figura 1). Fue objeto de investigaciones arqueológicas dirigidas por Eduardo Cigliano y Rodolfo Raffino en las décadas de 1960 y 1970 (Raffino, 1984; Raffino, Cigliano y Manzur, 1976), focalizadas en el registro planimétrico y arquitectónico del asentamiento y la realización de numerosas excavaciones de recintos y tumbas.

Según estos relevamientos, el asentamiento se ubica sobre una meseta elevada sin sistema defensivo artificial, en asociación directa con terrenos de explotación agrícola del fondo del valle. Su superficie se encuentra ocupada por más de 530 recintos de piedra que responderían a diferentes funcionalidades como habitaciones, patios, calles, espacios abiertos, basurales, etc. Asimismo, se registró la presencia de una gran cantidad de tumbas de adultos y de un espacio de características particulares ubicado hacia el sector central del sitio. Se trata de un espacio semicerrado, delimitado por muros, en sus lados sur y norte, que fue denominado "canchón". Su planta es rectangular, cubre un área de aproximadamente $1.875 \mathrm{~m}^{2}$ y su superficie habría sido limpiada, despedrada y nivelada artificialmente. Las características y localización de esta estructura especial condujeron a los investigadores a plantear una división del asentamiento en dos mitades: una "población alta" hacia el Oeste (en la parte más elevada del pie de monte) y una "población baja" hacia el Este, en terreno de menor altitud y más cercano al río. Esta bipartición, afirman, responde a una organización social dual, en que dos facciones ocupaban sendas partes del sitio, constituyendo el "canchón" un espacio público de reuniones a modo de plaza (Raffino, 1984; Raffino et al., 1976).

Respecto a las unidades habitacionales del asentamiento, estos investigadores afirman que están conformadas por recintos simples o agrupados, estos últimos formando unidades compuestas de dos a ocho recintos interconectados por vanos, pero sin puertas que los comuniquen al exterior. Sin embargo, también detectaron algunas diferencias arquitectónicas entre las llamadas "población alta y "población baja". Esta última se compone de aproximadamente 260 recintos, entre los que se circulaba a través de calzadas claramente delimitadas. Allí predomina la construcción semisubterránea, conocida como "casa-pozo", donde un recinto es edificado a partir de la excavación de un pozo en el terreno cuyo contorno es luego revestido por un lienzo de piedras que aflora sobre la superficie. Para la construcción se utilizaron cantos rodados de colores claros. En la "población alta" las estructuras se distribuyen de manera más irregular y no se observan vías de circulación del mismo tipo que en la "población baja", sino que la circulación debió darse a través de espacios abiertos libres de construcciones. En esta parte, la edificación se dio a nivel del suelo, sin 
mayores excavaciones del terreno salvo para los cimientos, y utilizando lajas planas más oscuras (Raffino, 1984; Raffino et al., 1976).

Otros rasgos registrados en el sitio fueron las tumbas y los montículos. Respecto de las primeras, se trata mayoritariamente de cistas, cámaras subterráneas subcirculares u ovales de paredes de piedra para el enterratorio de adultos (Raffino, 1984). Las mismas se localizan principalmente entre las unidades habitacionales, en las vías de circulación y, en un único caso registrado hasta el momento, por debajo del piso de los recintos. También han identificado enterratorios de subadultos en urnas, en general directamente en tierra, en los caminos o, en menor medida, en el interior de los recintos. Con relación a los montículos, más frecuentes en la "población baja", Raffino (1984) sostiene que corresponden a sucesivas acumulaciones de basura y desechos, que en ocasiones poseen muros de contención y habrían oficiado como vías sobreelevadas de circulación interna.

Paralelamente al relevamiento arquitectónico y espacial, Cigliano y Raffino desarrollaron excavaciones en 18 recintos de habitación, 20 cistas, 25 sitios de entierro de subadultos, en el "canchón", en basurales y en calzadas. Los hallazgos incluyeron materiales cerámicos, líticos, metálicos, textiles, de madera y de hueso y restos faunísticos y botánicos, cuyo análisis fue desarrollado en ambas publicaciones citadas (Raffino, 1984; Raffino et al., 1976).

Con posterioridad a estas investigaciones, El Churcal permaneció sin nuevas intervenciones hasta que, en la década del 2000, Lidia Baldini y su equipo retomaron su estudio con el objetivo de aportar a la distinción de la especificidad y variabilidad de las manifestaciones materiales y prácticas sociales al interior y entre los asentamientos tardíos de la región. Su abordaje se enfocó en la recuperación y análisis de información y materiales producto de esas primeras investigaciones en El Churcal, en la realización de nuevas excavaciones sistemáticas de unidades habitacionales, en el registro de rasgos arquitectónicos y topográficos y en el inicio del relevamiento planimétrico del asentamiento (Baldini, 2010, 2014; Baldini, Dulout, Ferreira, Sprovieri, Villamayor y Zilio, 2007; Baldini y Sprovieri, 2009; Ferreira, 2012; Sprovieri, 2008-2009). Como continuidad de estos trabajos, en los últimos años nos encontramos desarrollando estudios sobre distintas materialidades y contextos, en vinculación a prácticas domésticas al interior del sitio, así como de circulación y consumo de bienes (Barbich, 2018; Sprovieri, 2013; Sprovieri, Baldini y Rivera, 2019).

Los más recientes relevamientos de Baldini permitieron una aproximación más detallada y a nivel cuantitativo de algunos aspectos relativos a la instalación, las características constructivas y la distribución de las estructuras de una parte de El Churcal. Sus registros se concentraron en el área noreste de la llamada "población baja" por Raffino (1984), alcanzando un relevamiento planimétrico de 95 recintos y 23 cistas.

Se planteó que en ese sector los recintos son mayoritariamente de planta subrectangular o subcuadrangular, de ángulos redondeados, sin mortero ni revoque, salvo en dos casos en que se reconoció la presencia del primero. También se identificó que la materia prima utilizada para la construcción fueron rocas redondeadas que han sufrido un importante arrastre, procediendo probablemente del lecho del río Calchaquí (Baldini et al., 2007). En cuanto a la composición de las viviendas, predominan las compuestas por un solo recinto $(63,6 \%)$, seguidas por las integradas por dos $(10,6 \%$ y finalmente algunas complejas de más de dos (3\%) (Baldini et al., 2007). La consideración de los tamaños mostró la existencia de heterogeneidad en las superficies de los recintos, que varían en un rango amplio de 20 a $70 \mathrm{~m}^{2}$ (con algunas de mayores dimensiones) (Baldini, 2010; Baldini et al., 2007), aunque el $62 \%$ se ubica entre 30 y $60 \mathrm{~m}^{2}$ (Ferreira, 2012). Además, respecto de las unidades compuestas por recintos intercomunicados, se observa una sucesiva segmentación del espacio interior (Baldini, 2010). En la mayoría de las unidades dobles o múltiples la circulación es distribuida, con un único caso de no 
distribuida. Además, en las unidades múltiples, las relaciones son siempre asimétricas, mostrando una mayor dependencia entre los espacios y la existencia de espacios redistributivos (Ferreira, 2012). Todos estos aspectos llevaron a plantear en El Churcal la existencia de un mayor tamaño y una mayor diferenciación en algunas unidades, en relación con otros asentamientos contemporáneos de la región (Baldini, 2010).

Finalmente, en cuanto a la cronología del asentamiento, las primeras investigaciones señalaron que su ocupación se restringiría al PDR. Esta afirmación se basó en las características arquitectónicas y de los materiales recuperados y en la obtención de un fechado radiocarbónico sobre madera de una tumba que arrojó un resultado de $740 \pm 50 \mathrm{AP}$ -C.S.I.C. 434- (Raffino, 1984, p. 258). Su calibración actual con 1 sigma arrojó un rango de edad de $1273-1383$ cal. d.C. y para dos sigma de $1228-1391$ cal. d.C. ${ }^{2}$. Además, como parte de las investigaciones de Baldini y equipo, se realizó un nuevo fechado radiocarbónico sobre un premolar humano procedente de una cista cuyo resultado fue de $511 \pm 42 \mathrm{AP}$ (AA85656) y de $1418-1452$ cal. d.C. (1 sigma) y 1397-1488 cal. d.C. (2 sigma) (L. Baldini, comunicación personal, 2009 en Sprovieri, 2013, p. 98) ${ }^{3}$. Al momento, estos últimos datos plantean la posibilidad de una ocupación que podría haberse extendido hacia los inicios del período Inka, aunque se requiere mayor información para su evaluación precisa.

\section{Nuevos estudios espaciales en El Churcal: relevamiento planimétrico y arquitectónico}

En continuidad con las investigaciones desarrolladas por Lidia Baldini, en 2016 retomamos los estudios espaciales en El Churcal, buscando ampliar en cantidad y profundidad los datos disponibles sobre este asentamiento.

Para ello, en primer lugar, se realizó una exploración detallada del asentamiento y los alrededores a fin de obtener una imagen más precisa de la instalación del poblado en relación a la topografía, su extensión territorial y la localización de rasgos y elementos particulares. Esta exploración se desarrolló mediante la utilización de imágenes satelitales, prospecciones en el terreno y el registro con sistema de posicionamiento satelital (GPS de mano).

Por otro lado, continuamos el relevamiento planimétrico de El Churcal, con el objetivo de obtener un plano que incorporara los avances obtenidos previamente por Baldini (Baldini, 2010; Baldini et al., 2007). Ante su notable extensión territorial y la multiplicidad de construcciones que contiene, en esta etapa se decidió focalizar el relevamiento planimétrico en una porción significativa del sitio ubicada hacia el Este. Esta porción se corresponde con aproximadamente el $75 \%$ de la llamada "población baja" por Raffino 4 . Esta elección se debe a que esa parte cuenta con relevamientos planimétricos parciales previos (Baldini, 2010; Baldini et al., 2007) y con el mayor caudal de información generada para el sitio hasta el momento (Baldini, 2010, 2014; Baldini y Baffi, 2007; Barbich, 2018; Ferreira, 2012; Raffino, 1984; Raffino et al., 1976; Sprovieri, 2013; entre otros).

\footnotetext{
2 La calibración se realizó con el programa Calib Rev 7.0.4 utilizando la curva de calibración shcal13.14c (Hogg et al., 2013). Los rangos y probabilidades para 1 sigma fueron $1273-1317$ cal. d.C. $(p=0,64)$ y $1354-$ 1383 cal. d.C. $(p=0,36)$, mientras que para 2 sigma fueron $1228-1254$ cal. d.C. $(p=0,07), 1256-1330$ cal. d.C. $(p=0,56)$ y 1334-1391 cal. d.C. $(p=0,37)$.

3 La calibración del fechado citado fue realizada con el programa Calib Rev. 5.1.0 utilizando la curva de calibración shcal04.14c (McCormac, Hogg, Blackwell, Buck, Higham y Reimer, 2004).

4 La porción relevada se aproximaría a las estructuras comprendidas dentro de las cuadrículas C1, C2, D1 y D2 del plano publicado por Raffino y colaboradores (1976), aunque el mismo presenta importantes diferencias con nuestras observaciones y relevamientos actuales.
} 
Para la realización del plano fueron considerados los rasgos topográficos actuales, así como los restos arquitectónicos, es decir, aquellos remanentes observables hoy en día en la superficie del terreno. El primer paso fue la realización de un croquis a mano alzada de las estructuras y sus relaciones, que después fue utilizado para orientar la toma de puntos con una Estación Total Nikon 5.C y el registro de referencias geoespaciales con GPS. Luego, los puntos fueron georreferenciados en QGIS y unidos mediante segmentos para la construcción del plano digital. Existen casos en los que la observación de los muros fue difícil debido a su conservación, al enterramiento o a la densa cobertura vegetal, por lo que parte de los trayectos de los muros fueron intuidos y registrados en el plano digital con línea punteada.

El nivel de detalle alcanzado en esa planimetría permitió avanzar en el análisis espacial de esta porción del asentamiento. Se consideraron variables cuantitativas y cualitativas para describir la composición, variabilidad, distribución y asociación de los elementos que la componen. En principio, fue posible identificar la existencia de distintos tipos de estructuras como recintos, cistas, caminos y otras edificaciones en piedra, junto con rasgos como montículos, espacios libres de construcciones, pozos, sectores de vegetación densa y rasgos topográficos. Posteriormente, se consideraron la cantidad, formas, tamaños y localización de cada uno de ellos. A su vez, cuando fue posible, se registraron ciertas características particulares, como pueden ser: la existencia de comunicación al exterior, posibilidades de circulación interna, características constructivas particulares, etc. Finalmente, se analizó la distribución y asociación de todos los elementos, lo que permitió evaluar diferencias y similitudes y considerar la existencia de sectorizaciones en esta porción del sitio.

\section{Sobre la estructuración espacial de El Churcal}

Las exploraciones y relevamientos que desarrollamos en El Churcal permitieron obtener nueva información espacial a dos niveles. Por un lado, con relación al asentamiento en general se precisaron sus características de emplazamiento y dimensiones; por otro, a nivel más acotado, se generó información arquitectónica y espacial más detallada sobre la porción este.

\section{Emplazamiento, dimensiones y límites del asentamiento}

En base a estas nuevas exploraciones podemos señalar que el asentamiento se encuentra emplazado en una terraza aluvial de forma muy irregular con sucesivos espolones que se abren en su gran mayoría hacia el Sur (uno de ellos hacia el Norte). La terraza se eleva $60 \mathrm{~m}$ por encima del nivel del lecho del río Calchaquí, que constituye el límite este de la formación. Por su parte, el límite oeste lo constituye la base de los cerros desde donde desciende la geoforma (cerros Negro y Colorado). El límite norte está determinado por una quebrada (Quebrada del Pimentón) y el sur por una sucesión de pequeñas quebradas que se forman a partir de los espolones. La terraza presenta una diferencia de altitud de $100 \mathrm{~m}$ entre sus extremos oriental, más bajo, y occidental. Sobre la superficie de esa terraza se distribuyen las estructuras que componen $\mathrm{EI}$ Churcal, ocupándola casi en su totalidad, aunque no de manera totalmente continua (Figura 2).

En cuanto a los límites más puntuales del sitio, Baldini y colaboradores (2007) señalaron la existencia de dos muros paralelos que contornean el sitio hacia Sudoeste, uno de ellos con abertura de ingreso al espacio del asentamiento. Respecto de ello podemos agregar que éste, el más cercano al sitio, presenta un trayecto levemente curvo siguiendo un sentido general oeste-este. Recorre unos $678 \mathrm{~m}$ desde el pie de los 


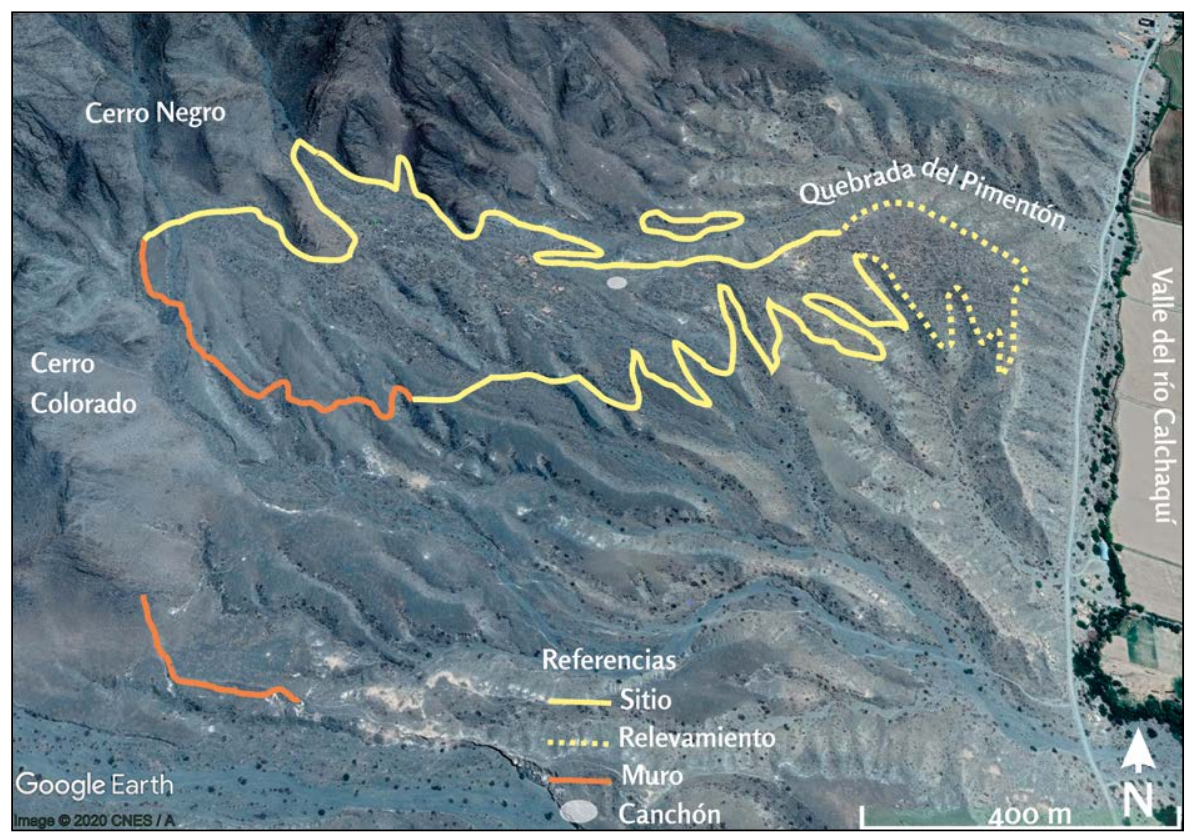

Figura 2. Imagen satelital de El Churcal con indicación del contorno del sitio, de la parte relevada planimétricamente y de los muros localizados al sur.

cerros ubicados al oeste hasta que se pierde su rastro. Se trata de un muro doble con relleno, construido con piedra de tipo pizarra que presenta caras planas naturales. En algunos tramos recorre el límite de la terraza, mientras que en otros la atraviesa sin coincidir con el contorno de la barranca (Figura 2).

Más hacia el Sur, a unos $400 \mathrm{~m}$ en línea recta desde el muro recién mencionado, se registra otro muro de características similares. En este caso, tiene más de un metro de ancho, su trayecto general es curvo y su sentido también Oeste-Este. Parte desde el pie del cerro Colorado, recorre una extensión de $285 \mathrm{~m}$, coincidiendo totalmente con el límite de la terraza donde se emplaza (Figura 2). En este caso, donde finaliza la misma, el muro parece no tener continuidad. Este muro linda con una quebrada de mayor envergadura que las demás asociadas al sitio, la cual parece comunicar el valle principal con espacios que se encuentran hacia el Oeste, es decir, por detrás de los cerros que marcan el límite occidental de El Churcal. Cabe destacar que entre estos dos muros no hemos detectado otro tipo de construcciones, es por ello que consideramos como límite sur del sitio el primero de los muros mencionados.

Por otro lado, sobre el extremo oeste del asentamiento, al pie del cerro Negro donde finalizan las construcciones, registramos un muro simple del cual no existían referencias anteriores. Se trata de un muro de unos cinco metros de largo asociado a un alineamiento de tres grandes rocas que podrían relacionarse con una demarcación física de parte del límite oeste del sitio. Además, hacia el Norte hemos detectado un nuevo sector de construcciones y recintos agrupados, del que no había menciones previas, ubicado al otro lado de la Quebrada del Pimentón, que se emplaza sobre el fondo de la cuenca y ocupa un área de 0,45 ha.

En suma, los límites del asentamiento se encuentran definidos por diferentes rasgos: hacia el Norte y este está delimitado por el mismo talud de la terraza; hacia el Oeste, por los cerros ya mencionados; finalmente, hacia el Sur, una parte por el talud de la terraza y otra por el primero de los muros meridionales mencionados. De esta manera, considerando todos estos nuevos datos, podemos señalar que el asentamiento de El 
Churcal ocupa una superficie de 32,85 ha. Dicha área no está plenamente cubierta por construcciones, sino que cuenta con espacios sin edificar.

Cabe destacar que la presencia de tramos de muros y algunos entierros en urnas en la pendiente de las barrancas, así como en el mismo fondo de la quebrada norte, nos muestra la existencia de límites no tan estrictos como los expresados. Sin embargo, podemos afirmar que no existe una continuidad en la construcción entre la terraza donde se asienta El Churcal y las terrazas contiguas hacia el Norte y el Sur, en las que al momento no hemos registrado evidencias de edificaciones.

Respecto de la distribución de las estructuras en la superficie del sitio, según nuestro registro éste se compone de áreas con diferentes densidades edilicias. Comenzando desde el Este, se observa una amplia zona con gran cantidad de construcciones y fuerte aglomeración, con mínimos espacios libres. Esta es la porción del sitio en la que se focaliza el relevamiento planimétrico y análisis espacial que se presenta la sección siguiente. Las características recién mencionadas se mantienen hasta un punto donde la geoforma se angosta, a partir del cual, si bien existe una notable cantidad de recintos y aglomeración, se observan mayores espacios libres. Luego de esta zona con construcciones, se observan unos $20 \mathrm{~m}$ libres de estructuras hasta el comienzo del denominado "canchón" que, como se ha mencionado, es un espacio delimitado por dos muros paralelos de sentido Este-Oeste (Baldini et al., 2007; Raffino, 1984). En nuestros relevamientos hemos identificado que su muro sur posee una abertura aproximadamente en su porción media y estimamos que pudo haber tenido otra, aunque no podemos confirmarlo debido a problemas de conservación. Además, resulta importante señalar que, si bien la superficie del "canchón" pudo haber sido intervenida para alcanzar un aspecto despejado y sin ondulaciones, como señaló Raffino (1984), la misma no se encuentra en un plano horizontal, sino que sigue la pendiente de la terraza, presentando un desnivel de ocho metros entre sus extremos occidental, más alto, y oriental.

Continuando hacia el Oeste, una vez traspasado el "canchón", se registran unos 80 $m$ de espacio libre de construcciones hasta el comienzo de una nueva zona con una importante cantidad de estructuras de estrecha aglomeración. Esta zona se extiende hasta el límite oeste del asentamiento y se prolonga hacia el sur, bordeando un pequeño peñón que se desprende del cerro Negro. Desde donde finaliza esa prolongación de construcciones hacia el sur, se observa un espacio libre de estructuras hasta el primer muro sur, que abarca un área aproximada de 6 ha. Más allá de ese muro no se ha registrado continuidad en la construcción.

\section{Arquitectura y organización espacial de la porción este del asentamiento}

En función del relevamiento planimétrico realizado nos fue posible conocer en detalle los elementos que componen esta porción del asentamiento y proporcionar una localización precisa para cada uno de ellos (Figura 3). A su vez, nos permitió registrar, contabilizar y comparar características arquitectónicas más específicas. Identificamos la existencia de distintos tipos de estructuras y rasgos, entre los que se encuentran recintos, cistas, vías de circulación, montículos y espacios libres de estructuras, cuyas características desarrollaremos a continuación.

\section{Recintos}

En esta porción registramos un total de 392 recintos, entendiendo que éstos se caracterizan por ser "espacios definidos por un límite discreto, en este caso un 


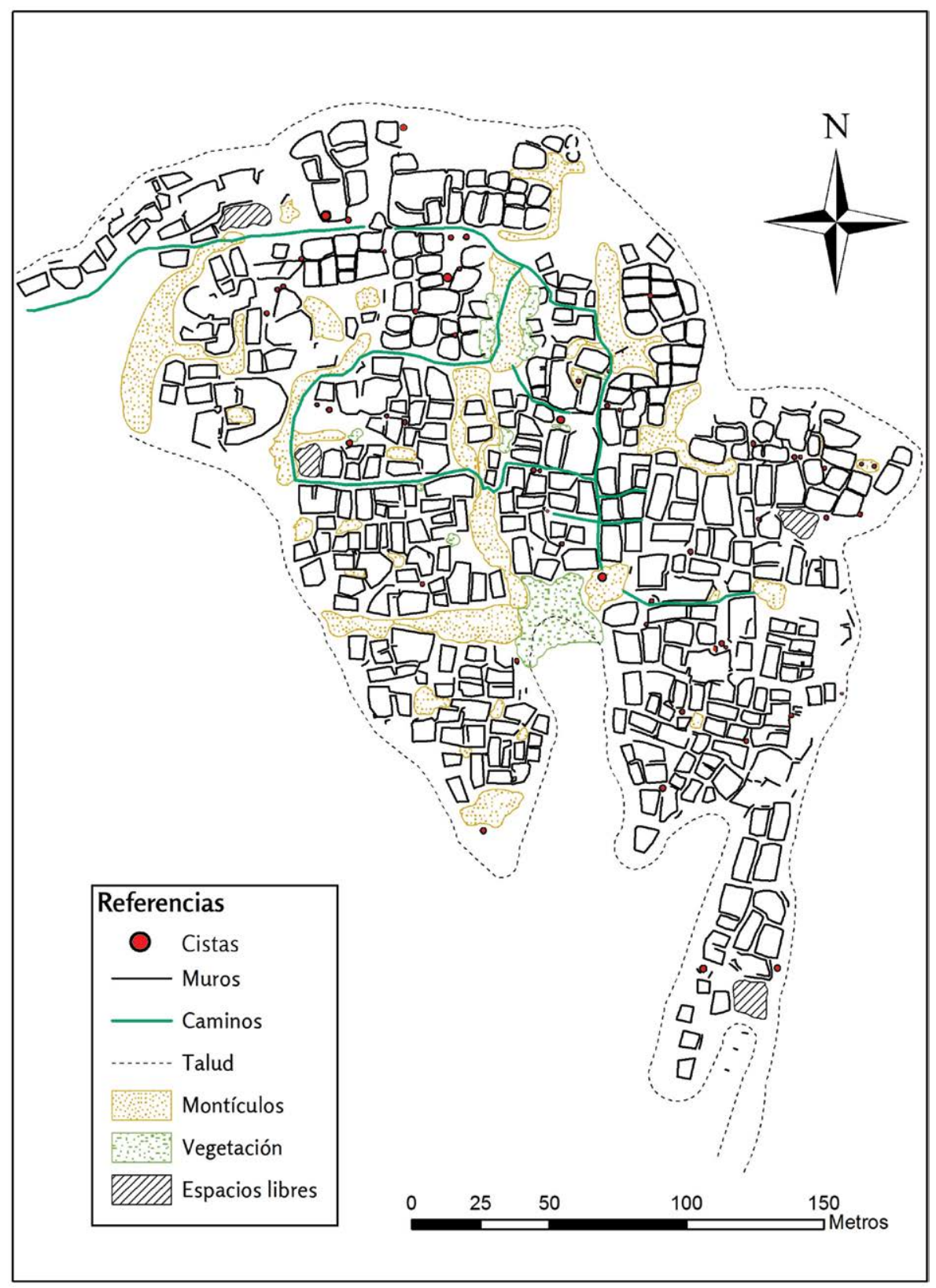

Figura 3. Planimetría de la porción este de El Churcal.

muro perimetral de piedra, que constituye y da forma a un espacio interno" (Ferreira, 2012, p. 1060). Pueden ser de distinto tipo: aislados, constituyendo unidades simples, o agrupados, conformando unidades compuestas por dos o más recintos interconectados. Entre estas últimas observamos casos de unidades dobles, triples, cuádruples, quíntuples y una séxtuple (Tabla 1, Figura 4A-F).

En principio, podemos señalar la existencia de una gran cantidad de recintos y una importante aglomeración. Además, si bien predominan las unidades simples, con este nuevo relevamiento se incrementó levemente la proporción de unidades compuestas $(17,1 \%)$ respecto de la planteada en trabajos anteriores (14\%) (Ferreira, 2012). Este aspecto debe continuar evaluándose en función del avance de la planimetría del resto del asentamiento y considerando que los porcentajes de trabajos previos 


\begin{tabular}{|l|c|c|c|}
\hline \multirow{2}{*}{ Tipo } & \multicolumn{2}{|c|}{ Cantidad de unidades } & \multirow{2}{*}{ Cantidad de recintos } \\
\cline { 2 - 3 } & Número & Porcentaje & 261 \\
Simple & 261 & 82,9 & 82 \\
Doble & 41 & 13 & 21 \\
Triple & 7 & 2,2 & 12 \\
Cuádruple & 3 & 0,95 & 10 \\
Quíntuple & 2 & 0,64 & 6 \\
Séxtuple & 1 & 0,31 & $\mathbf{3 9 2}$ \\
\hline Total & $\mathbf{3 1 5}$ & $\mathbf{1 0 0}$ & \\
\hline
\end{tabular}

Tabla 1. Cantidad de recintos y unidades por tipo.

A
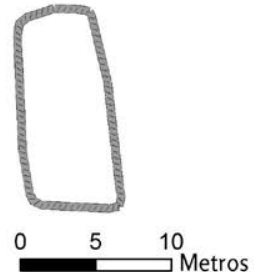

Metros

D

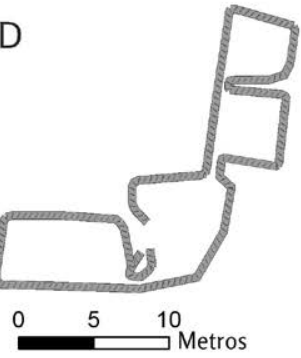

G

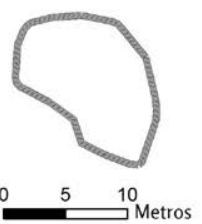

B

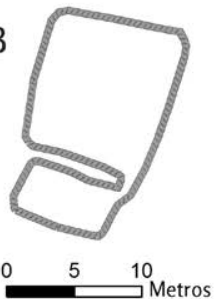

$\mathrm{E}$

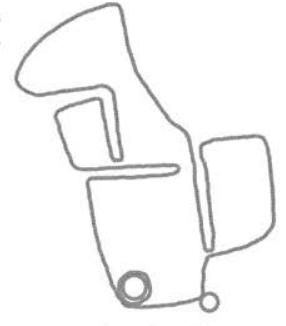

-5 invers

$\mathrm{F}$

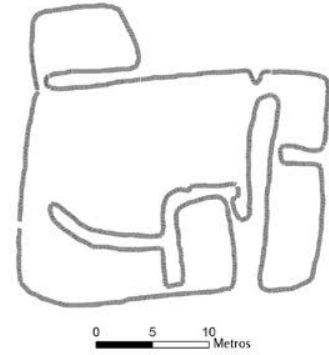

I

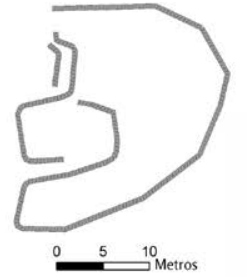

C

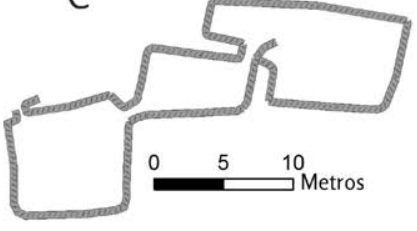

$\mathrm{H}$

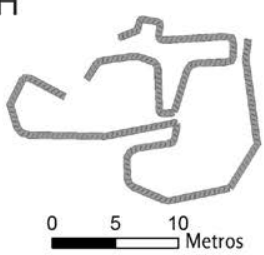

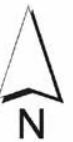

Figura 4. Tipos y formas de recintos. A) Recinto simple; $B$ ) Recinto doble; $C$ ) Recinto triple; D) Recinto cuádruple; E) Recinto quíntuple; F) Recinto séxtuple; G) Recinto irregular; $H$ ) Recinto en $L$; I) Recinto en $U$.

se obtuvieron para sectores que habían sido anteriormente excavados de manera intensiva.

Respecto a su morfología ${ }^{5}$, se observa una amplia predominancia de formas subrectangulares, identificadas en el $92,6 \%$ de los recintos $(N=363 / 392)$. En los

5 Para la determinación de formas se utilizan como referencia figuras geométricas. Sin embargo, empleamos el prefijo "sub" para dar cuenta de un ajuste imperfecto de las estructuras a las formas geométricas debido, 
casos restantes reconocimos, 16 recintos de formas irregulares, nueve en forma de $L$, dos en forma de $U$ y dos casos en que no pudo ser determinada debido a su pobre conservación (Figura 4A y G-I).

En cuanto a los tamaños de los recintos, medidos en área, registramos una gran variabilidad. Se observa una gradación entre los $5,82 \mathrm{~m}^{2}$ y los $124,13 \mathrm{~m}^{2}$, existiendo algunos casos esporádicos $(\mathrm{N}=14)$ de recintos de mayor tamaño (Figura $5 \mathrm{~A})$. Por otra parte, si consideramos los tamaños en relación con los tipos de unidades (Figura $5 B$ ), podemos observar que no existe una correspondencia entre área y cantidad de recintos que componen la unidad. Existen unidades dobles, triples y cuádruples de menor tamaño total que algunas unidades simples.

Otro aspecto que relevamos refiere a la existencia de aberturas de comunicación tanto de recintos hacia el exterior como entre recintos contiguos. Debido a factores como la falta de visibilidad por la cobertura vegetal o la mala conservación de los muros, este aspecto puede observarse parcialmente o con ciertas limitaciones.

En cuanto a la comunicación al exterior, pudimos determinar la existencia de una abertura únicamente en ocho casos (Figura 4C) y se sospecha esa posibilidad en otros 21, algo que podrá evaluarse con mayor precisión a partir de excavaciones. Sin embargo, pudimos confirmar la ausencia de abertura en una mayor cantidad de casos $(N=42)$, gracias a que se conserva todo el muro perimetral del recinto o de la unidad. Entre estos se encuentran muchos de los recintos excavados en su totalidad previamente por Raffino.

La existencia de pocos recintos con aberturas al exterior y un número mayor de casos confirmados con inexistencia de este tipo de elemento, junto a la utilización predominante de la técnica de "casa-pozo", indican que debieron existir otros modos de acceso a los recintos. En los casos en que existen diferencias de altura entre los pisos de los recintos y el terreno exterior ${ }^{6}$ el acceso podría haberse realizado mediante rampas (como se ha sugerido para otros sitios de la región, véase Ferrari, 2016; Kergaravat et al., 2015). En otros casos, la inclinación del terreno pudo permitir que parte de los pisos de los recintos queden a la misma altura que la superficie exterior.

En cuanto a la comunicación interna de las unidades compuestas, puede observarse que están dadas por una única abertura (Figura $4 \mathrm{~B}$ ) -salvo un caso que es doble (Figura 6A)-y siempre se encuentran en los ángulos del muro. Respecto a las unidades compuestas por más de dos recintos, podemos considerar otros aspectos como la conectividad interior. Al momento identificamos que la misma puede darse de tres maneras. Encontramos recintos que sólo conectan con uno (Figura 4C), otros que conectan con dos (Figura 4E) y algunos que conectan con tres (Figura 4F). Además, es de destacar que existen casos en que se requiere atravesar más de un recinto para conectarse con otro de la misma unidad (Figura 4F). Estas características marcan diferencias en cuanto a la circulación y conectividad de ciertos espacios al interior de las unidades, donde la conexión entre todos sus recintos no es uniforme. Esto podría hablar de una mayor o menor vinculación entre los espacios y sus actividades, en tanto algunos se conectan directamente y otros a través de uno u dos recintos intermedios (Figura 4C y 4D). Sin embargo, ante la escasez de información sobre los modos de acceso a las unidades desde el exterior (que podrían ser múltiples) y sobre

por ejemplo, a las diferencias en la longitud de los lados de los recintos, su orientación o la existencia generalizada de ángulos redondeados o lados curvos.

$6 \mathrm{El}$ análisis de la información de las excavaciones desarrolladas en recintos de este sector ha permitido sugerir que los niveles de ocupación se encontrarían a una profundidad de $1,1 \mathrm{~m}$ respecto a la superficie del terreno exterior actual (Barbich, 2018). 


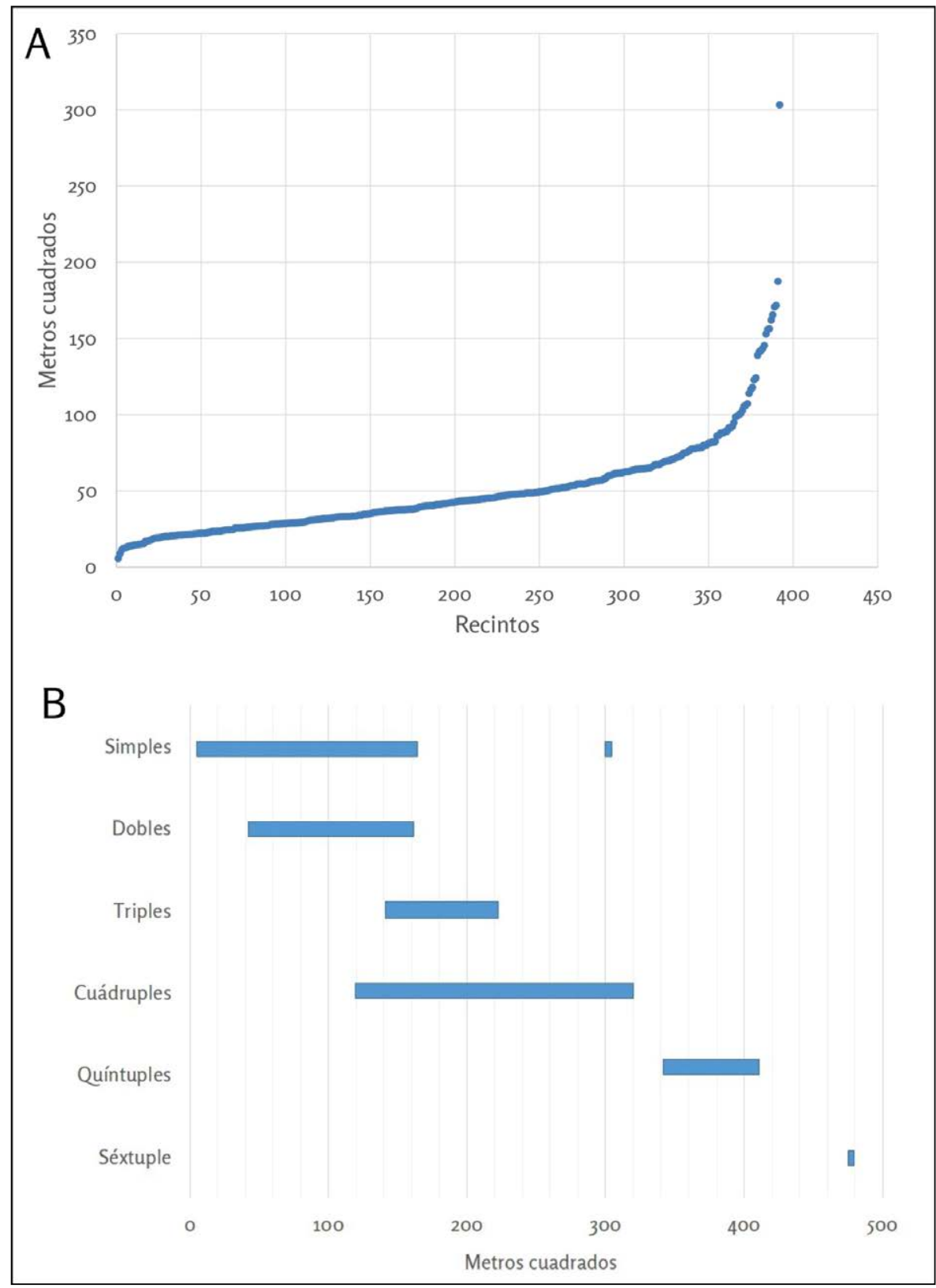

Figura 5. A) Gráfico de tamaños de los recintos en orden ascendente según su área; B) Gráfico de tamaños de las unidades según su tipo.

la existencia o no de techado, estas diferencias potenciales deberán ser exploradas a partir de nuevos y mayores datos.

Durante los relevamientos pudimos, además, observar algunas características constructivas particulares que aportan a la caracterización de la manera de construir los espacios en El Churcal. Si bien al momento no hemos desarrollado un registro individualizado de las técnicas constructivas de las estructuras, queremos destacar algunos aspectos que nos resultaron relevantes y que podrán, a futuro, ser considerados en función de próximos relevamientos en el asentamiento y comparados con otros sitios de la región:

a. Detectamos 33 casos de dos recintos contiguos, comunicados o no, en los que uno de los lados del muro perimetral de ambos es compartido, es decir fue construido en 


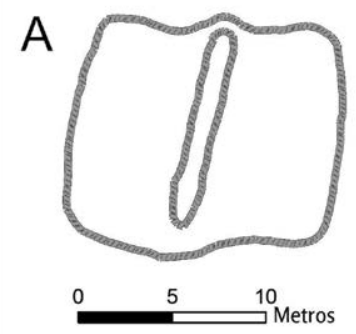

B

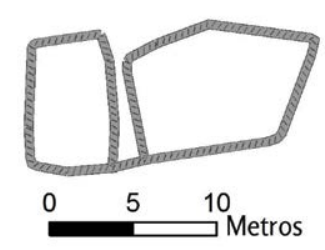

D

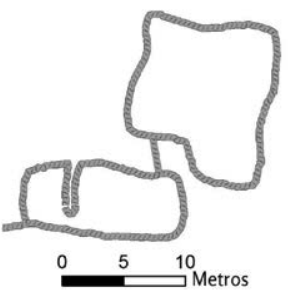

$E$

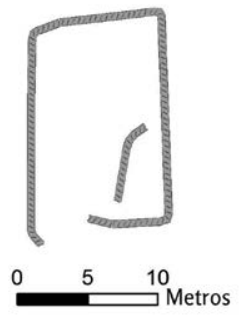

C
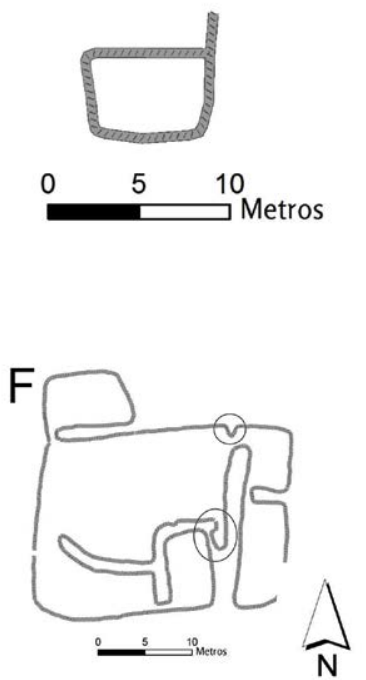

Figura 6. Casos de comunicación interna y rasgos constructivos particulares. A) Comunicación doble interna; B) Muro compartido; C) Muro que continua; D) Muro transversal; E) Muro interno; F) "Deflector" y "recoveco".

un único evento, de manera continua, independientemente de que fueran a constituir muros de recintos diferentes (Figura 6B).

b. Registramos 15 casos de recintos en los que uno de sus muros se proyecta y continúa por fuera, excediendo los límites del recinto, a pesar de que el perímetro del recinto se encuentre cerrado (Figura 6C).

c. En siete oportunidades observamos que entre dos recintos adyacentes en el espacio inter-edilicio conformado por el muro de uno y de otro, aparece una alineación de piedras, transversal a esos muros, pero sin atravesarlos (Figura 6D).

d. Identificamos que cinco recintos presentan evidencias de la existencia de un muro simple, en general corto y de técnica constructiva poco elaborada, en algún sector de su superficie interior, lo que plantea la posibilidad de algún tipo de división espacial interna (Figura 6E).

e. En cuatro casos -y siempre en relación con la abertura de comunicación entre dos recintos- reconocimos la presencia de una protuberancia en el muro perimetral a modo de "deflector". En la literatura, este tipo de rasgo suele vincularse al manejo de la circulación del aire, aunque en general se encuentra asociado a la abertura al exterior (Nielsen, 2001; Vaquer, Pey y Gerola, 2015). Aún resulta difícil plantear la función de este elemento en El Churcal, aunque no debe descartarse que haya influido en la visibilidad entre recintos (Figura 6F).

f. Finalmente, en cuatro recintos, alguna de sus esquinas presenta un espacio muy pequeño, conformado por la irregularidad del trayecto de los muros, que genera un tipo de "recoveco" (Figura 6F).

Por último, considerando parte de la información generada previamente, podemos realizar algunas observaciones respecto a la manera en que se habrían proyectado recintos y unidades. Al momento, los datos parecen indicar que las unidades triples, 
cuádruples, quíntuples y séxtuples habrían sido planificadas de esa manera, no siendo el resultado de subdivisiones posteriores de un espacio mayor. Esto se debe a que en muchos casos estas unidades compuestas parecen amoldarse a un espacio que habría quedado delimitado por la presencia de otros recintos, montículos o la misma topografía. En cuanto a las unidades dobles existe la posibilidad de que algunas sean el producto de la división de unidades originalmente simples. Esto lo sugiere el hecho de que el muro que las divide está construido independientemente del muro perimetral, pudiendo ser entonces un agregado (aunque esto no quita que pudo haber sido concebido conjuntamente también). Por otro lado, existen algunos indicios que apuntarían a que la planificación de unidades dobles desde un comienzo sería una práctica desarrollada en El Churcal. Por ejemplo, en un caso la distribución irregular de los recintos de una unidad doble en relación con el espacio disponible entre otras estructuras y montículos sugiere que fue concebido así originalmente, al igual que otro caso en que una irregularidad del muro perimetral de una unidad doble está en función del muro interno que divide a ambos recintos. Estas observaciones iniciales sugieren que la diversidad de tipos de unidades registradas en esta porción del sitio sería producto de una concepción original que así fue desarrollada en la práctica.

\section{Cistas}

Otra de las estructuras identificadas durante el relevamiento fueron las cistas. En la porción relevada alcanzan un total de 55 y en su inmensa mayoría se encuentran excavadas. Si consideramos que Raffino (1984) manifestó haber excavado sólo 20 tumbas de adultos en cistas, es muy posible que una gran parte de las que registramos hayan sido huaquedas. También podrían ser producto del huaqueo los 46 pozos que hemos detectado en la superficie de esta porción del sitio, por fuera de los recintos. Algunos de ellos, creemos, pueden coincidir con las excavaciones de entierros de infantes en urnas realizadas por Raffino en callejuelas, montículos y basurales, aunque el autor contabiliza 17 casos (Raffino, 1984).

En cuanto a su morfología, las cistas presentan forma mayoritariamente circular o subcircular (89\%), existiendo casos de cistas de planta subrectangular $(5,5 \%)$ y oval $(5,5 \%)$. Por otra parte, respecto al tamaño, se observa cierta variabilidad en tanto sus áreas oscilan entre los $0,5 \mathrm{~m}^{2}$ y los $5,8 \mathrm{~m}^{2}$. Se puede señalar una gradación desde las cistas más pequeñas hasta los $3 \mathrm{~m}^{2}$ aproximadamente y luego la existencia de algunos casos (cinco) de tamaños mayores. Si bien la información sobre las excavaciones de cistas y sus contenidos en la década de 1970 es reducida y fragmentaria, podemos señalar que aparentemente el tamaño no estaría inequívocamente relacionado con la cantidad de individuos inhumados. Así lo sugiere la información disponible sobre algunas de las cistas excavadas por Raffino, donde la № 109 (numeración de ese investigador) es una de las de mayor tamaño $\left(4,97 \mathrm{~m}^{2}\right)$ pero sólo contenía dos adultos, mientras que existen otras cistas que contienen hasta 11 cuerpos (Raffino, 1984). Finalmente, con relación a su localización, se observa que las cistas se distribuyen en distintos espacios de esta porción del asentamiento, como ya había sido señalado por otros investigadores (Baldini et al., 2007; Raffino, 1984). Casi de manera exclusiva se encuentran por fuera de los recintos, en montículos, caminos, espacios interedilicios o espacios libres de estructuras, existiendo un único caso, al momento, de una cista en el interior de uno de los recintos excavados por Raffino.

\section{Vías de circulación}

Investigaciones previas en El Churcal han distinguido la existencia de vías de circulación internas (Baldini et al., 2007; Raffino, 1984). En base a nuestro relevamiento y la 
exploración detenida de su superficie en esta porción del asentamiento, hemos podido identificar el trayecto de algunos tramos de caminos internos. Estos se distinguen con relativa claridad por encontrarse sobreelevados, por presentar delimitaciones con muros en parte de su recorrido y/o por quedar definidos por las estructuras que poseen a sus laterales.

Al momento se pudieron reconocer algunos trayectos de camino más notorios y de mayor extensión. Ubicándonos aproximadamente hacia el centro de la porción relevada, uno de ellos presenta una orientación Sur-Norte la que, llegando hacia el extremo norte del asentamiento, vira hacia el Oeste y continúa en esa dirección. Además, desde ese primer camino sur-norte se abren hacia el Oeste otros dos trayectos perpendiculares al primero. Más allá de estos tramos de caminos más notorios, también registramos otras vías que se desprenden del camino sur-norte hacia ambos lados (Este y Oeste), de características menos formales y no tan elevadas (Figura 3).

\section{Sectorizaciones y distribución espacial}

En función del relevamiento y caracterización realizada de las estructuras que componen esta porción del asentamiento y apelando a registros realizados durante los trabajos de campo, hemos podido detectar potenciales segmentaciones de ese espacio. Las mismas están dadas fundamentalmente por la distribución de los trayectos de los caminos más notorios y de los montículos, que determinan discontinuidades en la presencia de construcciones y operan como conductores de la circulación. A esto se le suma nuestra observación directa en el terreno que ha permitido registrar información sobre diferencias de altura, intermitencia en la continuidad de la construcción, etc. en localizaciones puntuales en el sitio. El resultado es la delimitación parcial de espacios que contienen conjuntos de estructuras y rasgos y que varían en la superficie que ocupan. En base a esto podemos plantear la existencia, a priori, de 10 sectores ( $1 \mathrm{a}$ 10) en esta porción de El Churcal (Figura 7).

Este primer reconocimiento de sectorizaciones espaciales nos abrió interrogantes sobre su posible vinculación con aspectos del funcionamiento y organización del asentamiento. Por esa razón, comenzamos a indagar en la existencia o no de diferenciaciones de algún tipo entre sectores a fin de generar evidencia que, junto a otra a obtener a futuro, permita precisar o reformular las sectorizaciones espaciales propuestas. Para evaluar esas semejanzas o diferencias consideramos las maneras en que se asocian y distribuyen los rasgos y estructuras relevadas y analizadas previamente. Las variables comparadas corresponden a cantidad, tipo (simple, doble, etc.) y tamaño (considerando tamaños máximos, mínimos y promedio) de los recintos, y cantidad y tamaño de las cistas (Tablas 2 y 3 ). No se consideraron en la comparación la forma de recintos y de cistas dada su alta homogeneidad a lo largo de toda la porción relevada, ni la presencia de ciertos rasgos constructivos, como existencia de aberturas, ya que son casos numéricamente escasos. Además, es importante destacar que las estructuras del sector 10 muestran una pobre conservación, ofreciendo una calidad de información más limitada, por lo que dicho sector no fue considerado en la siguiente comparación.

El análisis comparativo nos permitió observar algunas tendencias semejantes entre los diferentes sectores, aunque existen variaciones en ciertos casos. En primer lugar, se puede mencionar que en casi todos los sectores se encuentran representados los distintos tipos de estructuras reconocidas en esta porción del sitio. Las unidades simples y dobles, que son las más numerosas, se presentan en el $100 \%$ de los sectores. Ocho de los nueve sectores analizados muestran un porcentaje de unidades simples que varían entre 80 y 93\%, mientras que en siete de ellos las unidades dobles se dan 


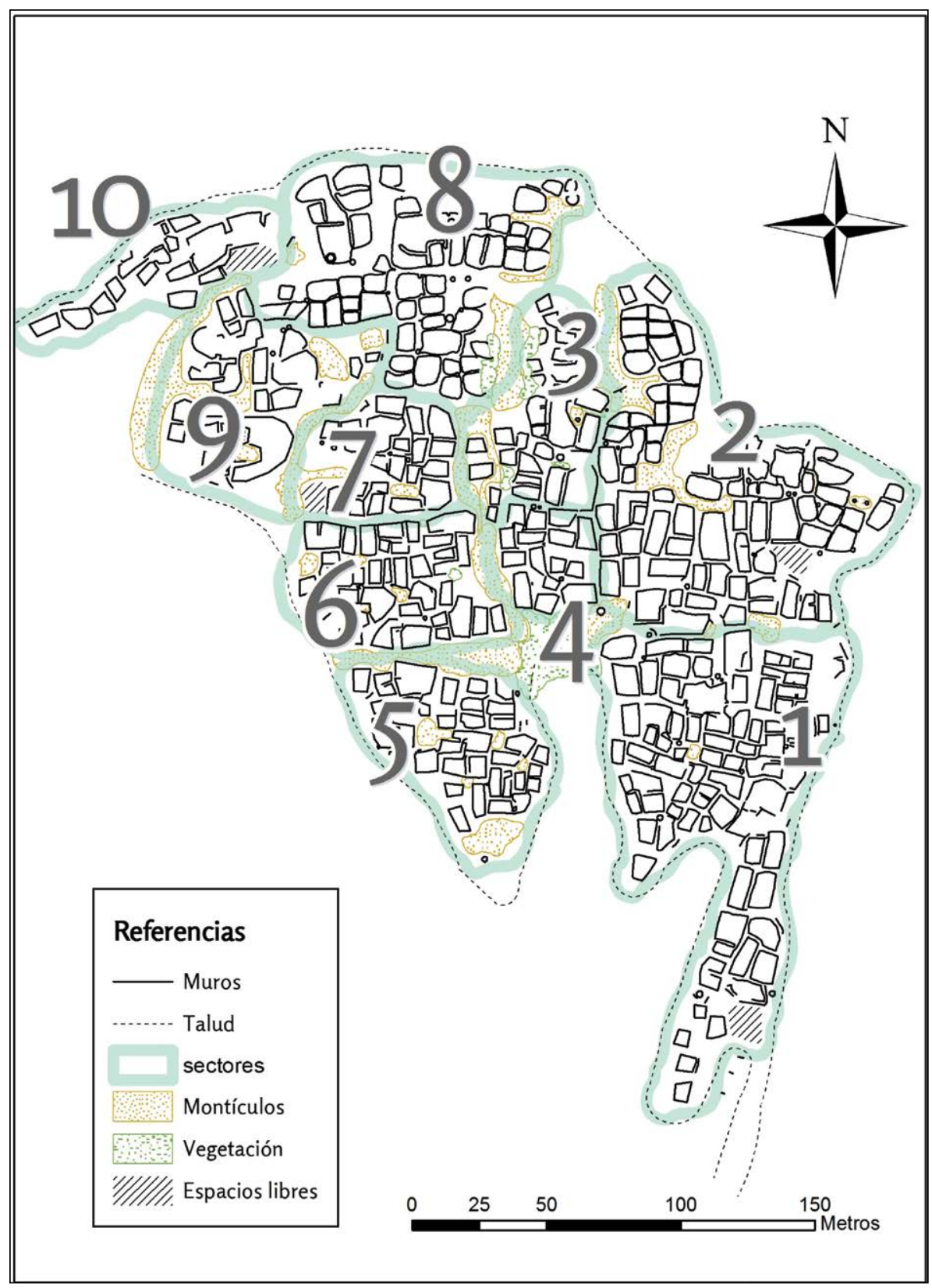

Figura 7. Planimetría de la porción este de El Churcal con indicación de sectores.

entre un 5,5 y $15 \%$. Respecto de las unidades múltiples (de entre tres y seis recintos), a pesar de representar el $4,1 \%$ del total de unidades del sitio se encuentran presentes en seis de los nueve sectores, en porcentajes de entre el 4,7 y 13,63\% (Tablas 2 y 3 ).

En vinculación al tamaño de los recintos, observamos una similitud general en las áreas máximas y mínimas y en las áreas promedio que ocupan los recintos de cada sector (Tablas 2 y 3 ). En 2/3 de los sectores, los tamaños mínimos oscilan entre 12,41 y 15,32 $\mathrm{m}^{2}$, mientras que los máximos entre 141,98 y $171,77 \mathrm{~m}^{2}$. A su vez, los promedios de las áreas de todos los recintos varían entre 42,04 y $52,56 \mathrm{~m}^{2}$ en ocho de los nueve sectores. Consideramos que estos rangos son bastante acotados, indicando una variabilidad semejante en las dimensiones de los recintos entre sectores.

Finalmente, las cistas se encuentran presentes en todos los sectores analizados, siendo una estructura ubicua en esta porción del sitio -representan el 14,86\% ( $N=$ 


\begin{tabular}{|c|c|c|c|c|c|}
\hline & Sector 1 & Sector 2 & Sector 3 & Sector 4 & Sector 5 \\
\hline$N^{\circ}$ de $R$ & 80 & 76 & 32 & 15 & 35 \\
\hline $\mathrm{N}^{\circ}$ de U & 63 & 70 & 25 & 14 & 22 \\
\hline $\mathrm{N}^{\circ}$ de $\mathrm{C}$ & 11 & 16 & 2 & 4 & 2 \\
\hline $\mathrm{N}^{\circ}$ de US & $\begin{array}{c}50 \\
(79,37 \%)\end{array}$ & $\begin{array}{c}64 \\
(91,43 \%)\end{array}$ & $\begin{array}{c}20 \\
(80 \%)\end{array}$ & $\begin{array}{c}13 \\
(92,86 \%)\end{array}$ & $\begin{array}{c}13 \\
(59,09 \%)\end{array}$ \\
\hline $\mathrm{N}^{\circ}$ de UD & $\begin{array}{c}10 \\
(15,87 \%)\end{array}$ & $\begin{array}{c}6 \\
(8,57 \%)\end{array}$ & $\begin{array}{c}3 \\
(12 \%)\end{array}$ & $\begin{array}{c}1 \\
(7,14 \%)\end{array}$ & $\begin{array}{c}6 \\
(27,27 \%)\end{array}$ \\
\hline $\mathrm{N}^{\circ}$ de UT & $\begin{array}{c}2 \\
(3,17 \%)\end{array}$ & $\begin{array}{c}0 \\
(0 \%)\end{array}$ & $\begin{array}{c}2 \\
(8 \%)\end{array}$ & $\begin{array}{c}0 \\
(0 \%)\end{array}$ & $\begin{array}{c}2 \\
(9,09 \%)\end{array}$ \\
\hline $\mathrm{N}^{\circ}$ de UM & $\begin{array}{c}1 \\
(1,58 \%)\end{array}$ & $\begin{array}{c}0 \\
(0 \%)\end{array}$ & $\begin{array}{c}0 \\
(0 \%)\end{array}$ & $\begin{array}{c}0 \\
(0 \%)\end{array}$ & $\begin{array}{c}1 \\
(4,54 \%)\end{array}$ \\
\hline Tamaño mín. de R (en ha) & 12,41 & 12,71 & 15,32 & 20,7 & 14,71 \\
\hline Tamaño máx. de R (en ha) & 162,15 & 165,78 & 171,77 & 86,17 & 156,44 \\
\hline Tamaño promedio de R (en ha) & 50,18 & 52,43 & 42,07 & 47,60 & 42,02 \\
\hline
\end{tabular}

Tabla 2. Cantidad de recintos, unidades y cistas, y tamaño de recintos en ha. para los sectores 1 a 5 . Referencias: R: recintos; U: unidades; C: cistas; US: unidades simples; UD: unidades dobles; UT: unidades triples; UM: unidades múltiples.

\begin{tabular}{|c|c|c|c|c|c|}
\hline & Sector 6 & Sector 7 & Sector 8 & Sector 9 & Sector 10 \\
\hline$N^{\circ}$ de $R$ & 37 & 20 & 57 & 23 & 17 \\
\hline$N^{\circ}$ de $U$ & 31 & 15 & 42 & 18 & 15 \\
\hline$N^{\circ}$ de $C$ & 1 & 5 & 11 & 3 & 0 \\
\hline$N^{\circ}$ de US & $\begin{array}{c}27 \\
(87,1 \%)\end{array}$ & $\begin{array}{c}10 \\
(66,66 \%)\end{array}$ & $\begin{array}{c}34 \\
(80,9 \%)\end{array}$ & $\begin{array}{c}16 \\
(88,9 \%)\end{array}$ & $\begin{array}{c}14 \\
(93,3 \%)\end{array}$ \\
\hline $\mathrm{N}^{\circ}$ de UD & $\begin{array}{c}3 \\
(9,7 \%)\end{array}$ & $\begin{array}{c}5 \\
(33,33 \%)\end{array}$ & $\begin{array}{c}6 \\
(14,3 \%)\end{array}$ & $\begin{array}{c}1 \\
(5,5 \%)\end{array}$ & $\begin{array}{c}0 \\
(0 \%)\end{array}$ \\
\hline $\mathrm{N}^{\circ}$ de UT & $\begin{array}{c}0 \\
(0 \%)\end{array}$ & $\begin{array}{c}0 \\
(0 \%)\end{array}$ & $\begin{array}{c}0 \\
(0 \%)\end{array}$ & $\begin{array}{c}0 \\
(0 \%)\end{array}$ & $\begin{array}{c}1 \\
(6,7 \%)\end{array}$ \\
\hline $\mathrm{N}^{\circ}$ de UM & $\begin{array}{c}1 \\
(3,2 \%)\end{array}$ & $\begin{array}{c}0 \\
(0 \%)\end{array}$ & $\begin{array}{c}2 \\
(4,7 \%)\end{array}$ & $\begin{array}{c}1 \\
(5,5 \%)\end{array}$ & $\begin{array}{c}0 \\
(0 \%)\end{array}$ \\
\hline Tamaño mín. de R (en ha) & 13,85 & 21,19 & 8,79 & 14,7 & 5,82 \\
\hline Tamaño máx. de R (en ha) & 113,97 & 141,98 & 187,78 & $\begin{array}{c}303,26 \\
\text { (sin considerar recinto } \\
\text { excepcional: } 156,07 \text { ) }\end{array}$ & 170,79 \\
\hline Tamaño promedio de R (en ha) & 46,35 & 52,56 & 45,67 & $\begin{array}{c}68,86 \\
\text { (sin considerar recinto } \\
\text { excepcional: } 58,20 \text { ) }\end{array}$ & 54,4 \\
\hline
\end{tabular}

Tabla 3. Cantidad de recintos, unidades y cistas, y tamaño de recintos en ha. para los sectores 6 a 10. Referencias: R: recintos; U: unidades; C: cistas; US: unidades simples; UD: unidades dobles; UT: unidades triples; UM: unidades múltiples.

55/315) de la totalidad de las construcciones-. Su cantidad por sector es variable, encontrándose entre una y 11 cistas por sector. Sin embargo, en seis de los nueve sectores se presentan en la proporción de una cista cada tres a seis unidades arquitectónicas (Tablas 2 y 3 ).

Estas tendencias generales semejantes detectadas entre los diferentes sectores parecen indicar que, en principio, no habría una amplia y contundente diferenciación entre ellos. A esto se suma que todos ellos están asociados a montículos y tramos de caminos, con un nivel similar de conexión, ya que esa asociación facilita el acceso y circulación sin mayores restricciones de sector a sector. 
Sin embargo, también creemos que aquellos casos que se han apartado de dichas tendencias deberán ser tenidos en cuenta en función del avance que realicemos en el estudio de la organización y funcionalidad de distintos espacios al interior del sitio. Entre esos casos podemos mencionar algunos sectores que presentan una llamativa baja cantidad de cistas, sobre todo en proporción a las unidades arquitectónicas. Este es el caso de los sectores 3,5 y 6 (Tablas 2 y 3 ). Debemos evaluar si esto pudiera deberse a factores como la mala conservación de las estructuras o su escasa visibilidad superficial, a la presencia de cistas al interior de los recintos (rasgo que ya ha sido observado en un caso en El Churcal) o a la existencia de otras modalidades funerarias como entierros directos en tierra, práctica identificada en otros sitios. De igual manera, deberemos considerar también la posibilidad de que la cantidad y proporción de cistas sea efectivamente baja en algunos sectores, lo que nos plantearía que esos espacios pudieron haber sido utilizados de una manera diferente.

Algunos sectores han mostrado valores diferenciales de algún tipo de unidad arquitectónica, como el sector 5 con menor proporción de simples, el 7 con menor cantidad de simples y sin múltiples, el 4 sin múltiples o el sector 8 que presenta dos de las tres unidades quíntuples y séxtuples totales que se relevaron (Tablas 2 y 3 ). Es necesaria mayor cantidad de información para evaluar si esto se debe a una práctica intencional, a una funcionalidad diferente $\mathrm{o}$ a problemas de visibilidad en el terreno. En el caso del sector 8 hay que tener en cuenta que corresponde al área que presentó la mayor cantidad de excavaciones de Raffino y por lo tanto información más completa de los tipos de estructuras, visibilidad de los muros y su articulación interna.

Por último, queremos destacar el caso del sector 9 que presenta un recinto simple de gran tamaño: es el mayor de todos los simples del sitio y se aparta notoriamente del simple siguiente más grande $\left(303,26 \mathrm{~m}^{2} \mathrm{vs} .165,58 \mathrm{~m}^{2}\right)$. A su vez, presenta una forma de U, diferente a la subrectangular predominante en la porción relevada (Figura 4I). Este caso resulta interesante ya que se trata de un espacio único con características particulares que nos lleva a preguntarnos sobre su posible uso para actividades especiales o de una escala mayor.

Estos distintos aspectos podremos ir evaluándolos en función de relevamientos más extensivos del asentamiento, de la realización de excavaciones y del análisis de distintas materialidades que se encuentran en proceso y se proyectan a futuro. A partir de todo ello se podrá ir avanzando en la precisión o el replanteo de las sectorizaciones espaciales aquí propuestas.

\section{Consideraciones finales}

Las nuevas investigaciones que desarrollamos en El Churcal amplían y precisan la información sobre distintos aspectos de la espacialidad y arquitectura del poblado. A nivel del asentamiento en general, pudieron precisarse los límites del espacio construido y registrarse nuevos conjuntos de estructuras, lo que permitió estimar una extensión precisa de 32,85 ha para El Churcal. Se confirma entonces la envergadura de este asentamiento, cuyas dimensiones superan ampliamente el promedio de otros asentamientos contemporáneos de la región que no exceden las 8 ha aproximadamente (por ejemplo, La Paya, Mariscal, Borgatta, el área residencial de Las Pailas, etc.) (Figura 1).

En su interior se destacan dos rasgos. Por un lado, la existencia de un muro al sur, de destacable extensión, que establece un límite claro al área con edificaciones. Su construcción parece implicar la necesidad de una delimitación física del espacio del asentamiento y nos hace reflexionar sobre la posibilidad de que se trate de una estrategia 
defensiva o bien de guiar y/o controlar el ingreso al sitio por el sur. El otro rasgo destacable es el "canchón", que ya ha sido resaltado y descrito por otros investigadores como un espacio público (Raffino, 1984, p. 234). Desde nuestro relevamiento podemos señalar que se encuentra un tanto separado de otras estructuras o conjuntos. Entre el "canchón" y el comienzo de la línea de construcciones existen $80 \mathrm{~m}$ hacia un lado y $20 \mathrm{~m}$ hacia el otro, sugiriendo una intención de no construir recintos cercanos a pesar de existir superficie apta y disponible. Esto, sumado a la gran extensión que abarca el "canchón", generaría un espacio libre más amplio para una posible congregación o potencial desarrollo de actividades de dimensión pública.

Respecto a esta estructura, también se ha sostenido que marcaría una división del sitio en dos partes: una "población alta" al Oeste y una "baja" al Este, que se diferenciarían en las técnicas arquitectónicas y materias primas empleadas. Si bien el "canchón" se localiza aproximadamente en un punto medio del sitio en su eje longitudinal, consideramos que las distinciones detectadas entre esas dos partes no están espacialmente tan diferenciadas. La utilización de piedra laja, supuestamente característica de la "población alta", también la hemos observado en construcciones que están al este del "canchón" y por lo tanto corresponderían a la "población baja". Además, si bien aún se requieren registros más sistemáticos, consideramos que la construcción semisubterránea, que sería propia de la "población baja", también se encuentra presente en la "población alta", aunque con algunas diferencias debido a la mayor pendiente del terreno en esta última. Sin embargo, no significa que el "canchón" no funcionara como un espacio divisorio, sino que, si efectivamente así lo hiciera, dicha división no tendría una correspondencia tan estrecha con las características arquitectónicas que habían sido señaladas.

En cuanto a la porción este de El Churcal, que relevamos a nivel planimétrico y arquitectónico, podemos señalar la magnitud de la intervención constructiva de este espacio dada la cantidad de estructuras y su alta aglomeración. Como mencionamos previamente, la porción relevada se corresponde con gran parte (el 75\%) de lo que Raffino consideraba la "población baja", a la cual le había otorgado una cantidad de 260 recintos. En nuestro relevamiento registramos un total de 392 recintos, un número considerablemente mayor ( $50 \%$ más) a lo que se conocía hasta el momento.

El tipo de estructuras y rasgos presentes en la porción relevada habían sido mencionados en investigaciones previas. Sin embargo, con este nuevo relevamiento contamos con un registro numéricamente mayor y una localización precisa de cada uno de ellos. De esta manera, se propició un acercamiento cuantitativo más representativo de las características arquitectónicas de esta porción, junto con un análisis más ajustado de la asociación y distribución de estructuras y rasgos. En base a ello pudimos establecer los porcentajes de los distintos tipos de recintos (simples, doble, etc.) y reconocer la existencia de un mayor número de unidades múltiples que el conocido hasta el momento, no encontrándose restringidas fuertemente a un único sector. Se reconoció a un nivel cuantitativo mayor la homogeneidad existente en las morfologías de recintos y cistas y la variabilidad en sus tamaños, señalándose aquellos casos extremos que se apartan de los rangos generales. Asimismo, se identificó una superposición en cuanto a los valores de las superficies que ocupan recintos simples y unidades compuestas, sugiriendo que se habrían planificado espacios de características diversas, especialmente entre los simples que muestran una gran variación de tamaño.

Fue posible trazar de manera efectiva la localización y recorrido de caminos y montículos, de los que hasta el momento sólo contábamos con la mención de su existencia. También se pudo reconocer, registrar y analizar ciertos rasgos constructivos particulares, algunos previamente mencionados como recovecos, tabiques o 
deflectores y otros novedosos como muros compartidos, muros que se proyectan, muros internos, etc. Gracias a ello, junto al más amplio y detallado registro de las aberturas de comunicación entre recintos y al exterior, se posibilitó comprender cómo ciertos espacios construidos, aunque no estuvieran directamente conectados, habrían sido concebidos y ejecutados en conjunto. Esto también lo indica el análisis de la distribución de las distintas estructuras y rasgos que muestra cómo ciertos grupos de recintos "encajan" en espacios que quedan delimitados por otros rasgos como montículos, otros recintos, la topografía, etc.

La diversa información generada nos permite plantear la posibilidad de que distintos recintos se hayan construido y utilizado de manera diferencial en esta porción del asentamiento. Así lo sugiere el hecho de que al menos algunas de las unidades múltiples hayan sido planificadas como tales, por lo que se habrían concebido originalmente espacios de distintas características a las unidades simples predominantes. También, la existencia de una conectividad diferencial entre los espacios que componen las unidades múltiples (de triples a séxtuples), algunos más permeables que otros, sugiere la posibilidad de que estuvieran relacionados a actividades y usos disímiles. Por otra parte, los análisis permitieron detectar un recinto de forma inusual (en $\mathrm{U}$ ) y de dimensiones $\left(303 \mathrm{~m}^{2}\right)$ que sobresale notablemente por sobre los demás recintos simples. Su carácter único abre interrogantes sobre su posible funcionamiento diferencial.

Asimismo, la calidad y precisión de los datos obtenidos nos permitió proponer la existencia de 10 potenciales sectores al interior de esta porción del sitio. Dichos sectores están compuestos por conjuntos de recintos y cistas que se encuentran definidos por los trayectos de caminos y montículos que, al mismo tiempo de generar una discontinuidad en el espacio construido, posibilitan la comunicación entre los sectores. El análisis comparativo entre los sectores mostró, en principio, cierta homogeneidad en el tipo, forma, tamaño y proporción de estructuras que los componen, sin que ninguno se destaque por características únicas o especiales. Sin embargo, hemos señalado también algunos casos que se apartan de esta tendencia general, los que deberán ser considerados en función de futuros avances de investigación.

En síntesis, este relevamiento y análisis, que amplía notoriamente la información cuantitativa y cualitativa sobre la estructuración espacial de El Churcal, proporciona una visión más ajustada de la complejidad de este asentamiento tardío. Si bien parte de los rasgos identificados (espacio público, montículos, vías de circulación internas, recintos, cistas, conjuntos complejos, muro perimetral, sectorizaciones, etc.) se han observado en otros asentamientos de la región, aquí se encuentran todos representados y con cierto arreglo particular. Es posible ahora revalorizar al sitio no únicamente por sus grandes dimensiones, sino particularmente por la cantidad, diversidad, distribución y asociación de estructuras y rasgos, por la potencial utilización diferencial de espacios y por las sectorizaciones espaciales propuestas para su porción este, que plantean una más compleja organización del espacio respecto de la división en mitades anteriormente propuesta para el sitio por otros investigadores. Esta envergadura y complejidad que fuimos desglosando puede estar en función de un asentamiento que habría albergado un gran número de personas, independientemente de si toda su superficie fue ocupada al mismo tiempo. Esta población numerosa, para llevar adelante su existencia material, social y biológica, debió requerir y realizar una gran variedad de tareas y etapas de trabajo en diferentes espacios del asentamiento.

Estos avances aportan información de relevancia para la comprensión de los modos de construir y estructurar El Churcal y sus similitudes y particularidades respecto a otros 
poblados tardíos de la región. Con próximos avances en el relevamiento planimétrico, en excavaciones sistemáticas y en el análisis de materiales, podremos ir evaluando en mayor detalle la vigencia o modificación de las tendencias y los patrones identificados hasta este momento.

\section{Agradecimientos}

A la Comunidad Diaguita Kallchakí de El Churcal por recibirnos en su Comunidad y su Sitio Sagrado. A Cristina Scattolin por el generoso préstamo de la Estación Total. A Lucas Pereyra Domingorena por su ayuda en el retiro y devolución de la Estación. A Ana Paula Cevidanes y Sebastián Cohen por la colaboración en el relevamiento de El Churcal. A Sofía Gandini, Luis Vicente Coll, Isabel Alcón, Joaquín Izaguirre, Martín Marazzi, Guido Bonorino y Javier Góngora por su asesoramiento en el funcionamiento de la Estación Total y en la digitalización del plano. A los evaluadores anónimos, quienes con sus comentarios han contribuido a la mejora del manuscrito. Esta investigación fue financiada a través de subsidios del CONICET (PIP 0437) y la UNLP (11/N721). 


\section{Referencias bibliográficas}

» Acuto, F. (1999). Paisaje y dominación: La constitución del espacio social en el Imperio Inka. En A. Zarankin y F. A. Acuto (Eds.), Sed non Satiata. Teoría Social en la Arqueología Latinoamericana Contemporánea (pp. 33-75). Buenos Aires: Ediciones del Tridente.

» Acuto, F. (2007). Fragmentación versus integración comunal: Repensando el Período Tardío del Noroeste Argentino. Estudios Atacameños, 34, 71-95. http://dx.doi.org/10.4067/S071810432007000200005

» Acuto, F., Amuedo, C.; Kergaravat, M., Goldin, A. L. y Gamarra, L. (2008). Experiencias subjetivas en aldeas prehispánicas del valle Calchaquí norte: Arqueología de la vida cotidiana, prácticas y relaciones sociales durante el Período Prehispánico Tardío. En L. A. Borrero y N. Franco (Eds.), Arqueología del Extremo Sur del Continente Americano. Resultados de Nuevos Proyectos (pp. 11-54). Buenos Aires: Instituto Multidisciplinario de Historia y Ciencias Humanas, Consejo Nacional de Investigaciones Científicas y Técnicas

» Acuto, F., Troncoso, A. y Ferrari, A. (2012). Recognizing strategies for conquered territories: A case study from the Inka North Calchaquí Valley. Antiquity, 86(334), 1141-1154. https://doi. org/10.1017/S0003598X00048304

» Alfaro de Lanzone, L. (1985). Investigación arqueológica de la "Ciudad" Prehistórica de La Paya, Dpto. de Cachi, Provincia de Salta, R. Argentina. Beitrage Zur Allgemeinen Und Vergleichenden Archaologie, 7, 563-595.

» Baldini, L. (2010). El espacio cotidiano. Las casas prehispánicas tardías en el valle Calchaquí, Salta. En M. E. Albeck, M. A. Korstanje y M. C. Scattolin (Eds.), El Hábitat Prehispánico. Arqueología de la Arquitectura y de la Construcción del Espacio Organizado (pp. 53-75). San Salvador de Jujuy: Editorial de la Universidad Nacional de Jujuy y Red de Editoriales de Universidades Nacionales de la Argentina.

» Baldini, L. (2014). Aproximaciones a las prácticas funerarias tardías del valle Calchaquí, Salta. Estudios Historia y Arqueología (Nueva Serie), 2, 7-26.

» Baldini, L. y Baffi, E. I. (2007). Aportación al estudio de prácticas mortuorias durante el Período de Desarrollos Regionales. Entierros en vasijas utilitarias del sector central del valle Calchaquí (Salta, Argentina). Revista Española de Antropología Americana, 37(1), 7-26. https://dx.doi. org/10.5209/REAA

» Baldini, L., Baffi, E. I., Quiroga, L. y Villamayor, V. (2004). Los Desarrollos Regionales en el valle Calchaquí, Salta. Relaciones de la Sociedad Argentina de Antropología, XXIX, 59-80.

» Baldini, L. y De Feo, C. (2000). Hacia un modelo de ocupación del valle Calchaquí Central (Salta) durante los Desarrollos Regionales. Relaciones de la Sociedad Argentina de Antropología, XXV, 74-98.

» Baldini, L., Dulout, L., Ferreira, M. E., Sprovieri, M., Villamayor, V. y Zilio, L. (2007). Avances en la investigación de El Churcal, valle Calchaquí, Salta. En XVI Congreso Nacional de Arqueología Argentina (Número Especial de Revista Pacarina), Tomo III (71-76). San Salvador de Jujuy: Facultad de Humanidades y Ciencias Sociales, Universidad Nacional de Jujuy.

» Baldini, L. y Sprovieri, M. (2009). Vasijas negras pulidas. Una variedad de la cerámica tardía del valle Calchaquí. Estudios Atacameños, 38, 21-38. http://dx.doi.org/10.4067/S071810432009000200003

» Baldini, L. y Villamayor, V. (2007). Espacios productivos en la cuenca del río Molinos (valle Calchaquí, Salta). Cuadernos de la Facultad de Humanidades y Ciencias Sociales - Universidad Nacional de Jujuy, 32, 35-51.

» Barbich, S. (2018). Contextos digitales: un primer paso en el estudio de espacios domésticos de El Churcal (Salta) a partir de datos presentados en GIS. Revista del Museo de La Plata, 3(1), suplemento resúmenes, $26 \mathrm{R}$. 
» D'Altroy, T., Lorandi, A., Williams, V., Calderari, M., Hastorf, C., DeMarrais, E. y Hagstrum, M. (2000). Inka rule in the Northern Calchaquí Valley, Argentina. Journal of Field Archaeology, 27, 1-26. https://doi.org/10.1179/jfa.2000.27.1.1

»DeMarrais, E. (1997). Materialization, Ideology and Power: The Development of Centralized Authority among pre-Hispanic Polities of the Valley Calchaquí, Argentina. (Tesis de Doctorado inédita), Universidad de California, Estados Unidos.

》Ferrari, A. (2012). Espacialidad local e Inka: Aportes a partir de un caso de estudio en el Valle Calchaquí Norte (Salta, Argentina). (Tesis de Licenciatura inédita), Universidad de Buenos Aires, Argentina.

» Ferrari, A. (2016). Espacialidad local e inka en el Valle Calchaquí Norte (Salta, Argentina): Reevaluando el alcance de la intervención imperial en La Paya. Estudios Atacameños, 53, 55-72.

»Ferreira, M. E. (2012). Estudio preliminar de los remanentes arquitectónicos del sitio EI Churcal, valle Calchaquí, Salta. En N. Kuperszmit, T. Lagos Mármol, L. Mucciolo y M. Sacchi (Comp.), Entre Pasados y Presentes III. Estudios contemporáneos en Ciencias Antropológicas (pp. 1056-1073). Buenos Aires: Mnemosyne.

» González, A. R. y Díaz, P. (1992). Notas arqueológicas sobre la Casa Morada. Estudios de Arqueología, 5, 13-45.

» Hayden, D. (1997). Urban landscape history: The sense of place and the politics of space. En P. Groth y T. Bressi (Eds.), Understanding Ordinary Landscapes (pp. 111-133). New Haven y Londres: Yale University Press.

» Hogg, A. G., Hua, Q., Blackwell, P. G., Niu, M., Buck, C. E., Guilderson, T. P., Heaton, T. J., Palmer, J. G., Reimer, P. J., Reimer, R. W., Turney, C. S. M. y Zimmerman, S. R. H. (2013). SHCal13 Southern Hemisphere calibration, 0-50,000 years cal BP. Radiocarbon, 55(4), 1889-1903. https://doi.org/10.2458/azu_js_rc.55.16783

»Ingold, T. (1993). The temporality of landscape. World Archaeology, 25, 152-174.

» Ingold, T. (2000). The Perception of the Environment. Essays on Livelihood, Dwelling and Skills. Londres y Nueva York: Routledge.

» Kergaravat, M. (2013). Los espacios de reunión en el paisaje social tardío del Valle Calchaquí Norte. Anuario de Arqueología, 5, 269-285. http://hdl.handle.net/2133/5071

» Kergaravat, M., Ferrari, A. y Acuto, F. (2015). Dinámica social y estructuración del espacio en el sitio Las Pailas (Valle Calchaquí Norte, Salta) durante el Período Tardío. Arqueología, 21, 89-109. https://doi.org/10.34096/arqueologia.t21.n0.2378

» McCormac, F. G., Hogg, A. G., Blackwell, P. G., Buck, C. E., Higham, T. F. G. y Reimer, P. J. (2004). SHCal04 Southern Hemisphere Calibration 0-11.0 cal kyr BP. Radiocarbon, 46, 10871092. https://doi.org/10.1017/S0033822200033014

» Nielsen, A. E. (2001). Evolución del espacio doméstico en el Norte de Lípez (Potosí, Bolivia): ca. 900-1700 DC. Estudios Atacameños, 21, 41-61.

»Páez, M. C., Giovannetti, M. y Raffino, R. (2012). Las Pailas. Nuevos aportes para la comprensión de la agricultura prehispánica en el Valle Calchaquí Norte. Revista Española de Antropología Americana, 42(2), 339-357. http://dx.doi.org/10.5209/rev_REAA.2012.v42. n2.40109

»Páez, M. C., Lynch, V. y Besa, Y. (2014). Espacios sagrados en el mundo andino. Excavación de una huanca en Las Pailas (Cachi, Salta, Argentina). Revista Española de Antropología Americana, 44(1), 275-284.

»Prieto, M. E., Besa, Y. C., Marinangeli, G. A., Riegler, E. F. y Páez, M. C. (2012). Los campos agrícolas de Las Pailas (Cachi, Salta). La Zaranda de Ideas. Revista de Jóvenes Investigadores en Arqueología, 8(2), 137-149.

» Raffino, R. (1984). Excavaciones en El Churcal (Valle Calchaquí, República Argentina). Revista del Museo de La Plata, VIII, Antropología 59, 223-263. 
» Raffino, R., Cigliano, E. y Manzur, M. E. (1976). El Churcal: un modelo de urbanización tardía en el valle Calchaquí. Revista del Museo de Historia Natural de San Rafael, 3(1), 33-42.

»Sprovieri, M. (2008-2009). Alucinaciones en circulación. Una mirada a la interacción surandina tardía desde las tabletas y tubos de La Paya (valle Calchaquí, Salta). Anales de Arqueología y Etnología, 63-64, 81-105.

»Sprovieri, M. (2013). El Mundo en Movimiento: Circulación de Bienes, Recursos e Ideas en el Valle Calchaquí, Salta (Noroeste Argentino). Una Visión desde La Paya. Oxford: British Archaeological Reports International Series 2487, Archaeopress.

» Sprovieri, M., Baldini, L. y Rivera, S. M. (2019). Identification of woods from museum archaeological collections: Use of local and non-local wood in pre-Columbian societies from Northwestern Argentina. Archaeological and Anthropological Sciences, 11, 1325-1343. DOI: https://doi.org/10.1007/s12520-018-0601-2

»Sprovieri, M. y Barbich, S. (2017). Rescatando un rescate: Revisión y análisis de un sector de La Paya a partir de un rescate arqueológico de 1981. Estudios. Antropología - Historia, Nueva Serie 4, 49-74.

» Tarragó, M. (1980). Los asentamientos aldeanos tempranos en el sector septentrional del valle Calchaquí, Provincia de Salta, y el desarrollo agrícola posterior. Estudios de Arqueología, 5, 29-53.

» Tarragó, M., Carrara, M. y Díaz, P. (1979). Exploraciones arqueológicas en el sitio SSalCac 14 (Tero), Valle Calchaquí. Antiquitas, 2, 231-242.

» Tarragó, M. y De Lorenzi, M. (1976). Arqueología del valle Calchaquí. Etnía, 23-24, 1-35.

» Tilley, C. (1994). A phenomenology of Landscape. Places, Paths and Monuments. Oxford: Berg Publishers.

» Vaquer, J. M., Pey, M. L. y Gerola, I. (2015). Paisaje y prácticas sociales en Cruz Vinto: una interpretación sobre la relación práctica-estructura en un pukara del Periodo de Desarrollos Regionales Tardío (1200-1450 DC). Intersecciones en Antropología, 16, 339-351.

»Villegas, M. P. (2011). Paisajes en movimiento. El uso del espacio durante los Períodos de Desarrollos Regionales e Inca en el Valle Calchaquí Medio (Salta, Argentina). Estudios Sociales del NOA, Nueva Serie 11, 63-82.

»Williams, V. I. (2004). Poder estatal y cultura material en el Kollasuyu. Boletín de Arqueología PUCP, 8, 209-245.

»Williams, V. I. (2010). El uso del espacio a nivel estatal. En M. E. Albeck, M. A. Korstanje y M. C. Scattolin (Eds.), El Hábitat Prehispánico. Arqueología de la Arquitectura y de la Construcción del Espacio Organizado (pp. 77-114). San Salvador de Jujuy: Universidad Nacional de Jujuy.

»Williams, V. I., Korstanje, A., Cuenya, P. y Villegas, M. P. (2010). La dimensión social de la producción agrícola en un sector del Valle Calchaquí Medio. En M. A. Korstanje, y M. Quesada (Eds.), Arqueología de la Agricultura: Casos de estudio en la región Andina Argentina (pp. 178207). Tucumán: Magna.

»Williams, V. I. y Villegas, M. P. (2017). Rutas y senderos como paisajes. Las quebradas altas del Valle Calchaquí Medio (Salta). Boletín del Museo Chileno de Arte Precolombino, 22(1), 7194. http://dx.doi.org/10.4067/S0718-68942017005000201 